\title{
Bond Strengths of Three Different Dentin Adhesive Systems to Sclerotic Dentin
}

\author{
Solen KARAKAYA ${ }^{1}$, Nimet UNLU ${ }^{1}$, Esra Can SAY², Fusun ÖZER ${ }^{1}$, Mubin SOYMAN² and Junji TAGAMI ${ }^{3}$ \\ ${ }^{1}$ Department of Operative Dentistry, Faculty of Dentistry, Selcuk University, Konya, Turkey \\ ${ }^{2}$ Department of Operative Dentistry, Faculty of Dentistry, Yeditepe University, Istanbul, Turkey \\ ${ }^{3}$ Department of Operative Dentistry, Tokyo Medical and Dental University, Tokyo Japan \\ Corresponding author, Solen KARAKAYA; E-mail: solen885@hotmail.com and karakaya@selcuk.edu.tr
}

\begin{abstract}
The two-fold aims of this study were: (1) to evaluate the microtensile bond strengths of different adhesive systems to sclerotic and sound palatal dentin; and (2) to observe the respective resin-dentin interfaces. Thirty extracted human incisor teeth were divided into two groups. Group I comprised sclerotic defects in the palatal zone. Group II comprised sound palatal dentin surfaces as control. Each group $(n=15)$ was divided into three subgroups according to dentin adhesive systems: self-etch (Clearfil SE Bond), total-etch (Scotchbond Multi-Purpose Plus), and glass ionomer (Reactmer Bond) adhesive systems. The specimens were subjected to tensile forces. Obtained data were analyzed by two-way ANOVA and post hoc Duncan's test. Fracture sites and resin-dentin interfaces were observed using a light microscope and SEM. With sound dentin, Clearfil SE Bond showed a significantly higher bond strength than the other adhesives $(p<0.05)$. With sclerotic dentin, although there were no significant differences in bond strength among the adhesives groups ( $p>0.05$ ), the bond strength values of Clearfil SE Bond and Scotchbond Multi-Purpose Plus were significantly decreased. On resin-dentin interface observation, different images were presented by different bonding systems.
\end{abstract}

Key words: Sclerotic dentin, Microtensile bond strength, Total-etch, Self-etch, Glass ionomer

Received Aug 8, 2007: Accepted Jan 14, 2008

\section{INTRODUCTION}

Wear of the natural dentition is a normal physiologic process that occurs throughout life. However, problems arise if the rate of loss or the degree of destruction becomes excessive, causing functional or esthetic problems or sensitivity for the patient ${ }^{1}$. The etiology of tooth wear is a multifactorial phenomenon involving acids and other tooth-softening chemicals, abrasion, tooth flexure ${ }^{2)}$ and attrition, each playing a role to a greater or lesser degree from patient to patient and tooth to tooth ${ }^{1,3,4)}$. The most common causes of excessive palatal wear are attributed to parafunctional activities such as bruxism, chemical erosion due to the introduction of gastric acid into the oral cavity occurring with repeated regurgitation $^{3)}$, and eating disorders such as anorexia nervosa or bulimia ${ }^{5}$. Loss of occlusal and palatal tooth tissues may result in changes in occlusal vertical dimension ${ }^{6}$, pulpal sensitivity, and weakening of the teeth, thereby requiring restorative treatment ${ }^{1,3,4)}$.

Enamel is the main tissue subjected to wear. However, advanced enamel wear exposes increasingly large areas of dentin. Compared to enamel, dentin is a more difficult bonding substrate due to its complex and variable histological features ${ }^{7}$. Accelerated partial or complete obliteration of the dentinal tubules with tube- or rod-like crystals and peritubular dentin forms sclerotic dentin ${ }^{8,9}$, which protects the pulp by rendering the dentin less susceptible to the effects of external stimuli ${ }^{10)}$. Depending on the sensitivity of the noncarious cervical lesion, varying levels of tubular patency may be observed, with most dentinal tubules being occluded with insensitive transparent dentin ${ }^{11)}$, thereby compromising the formation of resin $\operatorname{tags}^{8,12)}$.

The existence of a hypermineralized layer on the surface of noncarious cervical lesion and the presence of a layer of possibly remineralized denatured collagen at the bottom of the hypermineralized surface layer ${ }^{8,11}$ precludes optimal acid-etching of sclerotic dentin. Despite increased etching time, regional bond strength to sclerotic dentin was found to be lower than to sound dentin ${ }^{13-15)}$. An adhesive strategy involving micromechanical interlocking by the formation of a resin-dentin interdiffusion zone combined with resin tag formation into the dentinal tubules would be less effective when applied to the hypermineralized sclerotic dentin ${ }^{13)}$. The potential benefit of additional chemical interaction between functional monomers and tooth substrate components has recently gained new attention ${ }^{16)}$. The preservation of hydroxyapatite within the submicron hybrid layer of self-etch adhesives may serve as a receptor for additional chemical bonding ${ }^{16,17)}$.

The two-fold aims of the present study were: (1) to examine the bond strengths of different dentin adhesive systems (self-etch system: Clearfil SE 
Bond; total-etch system: Scotchbond Multi-Purpose Plus; and glass ionomer adhesive system: Reactmer Bond) to sound and sclerotic palatal dentin; and (2) to observe the changes in the resin-dentin interfaces with these adhesive systems. The null hypothesis was that there will be no differences in tensile bond strength between the adhesives at sound and sclerotic palatal dentin.

\section{MATERIALS AND METHODS}

\section{Tooth type and preparation}

Fifteen maxillary anterior teeth with deep natural sclerotic lesions on the palatal surface, and which were extracted for periodontal reasons, were used for bond testing in this study. Another 15 extracted sound maxillary anterior teeth were used as the control group.

The teeth were cleaned with an ultrasonic scaler to remove plaque and calculus. They were then stored in $0.5 \%$ chloramine-T solution at $4{ }^{\circ} \mathrm{C}$ and used within one month of extraction. In the control group, artificial palatal lesions (i.e., sound dentin) were prepared on the palatal surfaces of sound maxillary incisor teeth at the incisal and cervical margins in the same manner as the natural lesions $(4.0 \mathrm{~mm}$ wide and $3.0 \mathrm{~mm}$ deep). This was done using a high-speed handpiece (Compact Torque $636 \mathrm{P}, \mathrm{KaVo}$, Germany) with a tungsten carbide bur (FG 6, AD Burs, Gloucester, UK) under copious water cooling. A new bur was used for every five lesions. The artificial dentin surfaces of incisors in the control group were ground with 600-grit $\mathrm{SiC}$ paper to obtain flat dentin surfaces.

Both experimental and control groups were divided into three subgroups according to dentin adhesive systems (five teeth for each bonding system): self-etch (Clearfil SE Bond), total-etch (Scotchbond Multi-Purpose Plus), and glass ionomer (Reactmer Bond) adhesive systems. Five to six standardized sticks were made from each tooth, but only three to four suitable dentin sticks per tooth were chosen for bonding test use. Fifteen sticks were tested for each adhesive group, and the bonding systems were applied according to manufacturers' instructions.

Sclerotic dentin was visually identified according to the North Carolina Dentin Sclerosis Scale as reported by Heymann and Bayne ${ }^{18)}$ :

Category 1: No sclerosis is evident; dentin is opaque, light yellow or whitish in color with no discoloration. Little translucency or transparency is evident.

Category 2: Irregular translucency over less than

Table 1 Materials used in this study and their composition

\begin{tabular}{|c|c|c|c|c|c|}
\hline Adhesive Materials & Composition & Lot No. & $\begin{array}{l}\text { Restorative } \\
\text { Resin Materials }\end{array}$ & Lot No. & Manufacturer \\
\hline \multirow[b]{2}{*}{$\begin{array}{l}\text { SeIf-etch System } \\
\text { Clearfil SE Bond } \\
\text { (CSE Bond) }\end{array}$} & $\begin{array}{l}\text { Primer : } 10 \text { MDP, HEMA, } \\
\text { hydrophilic dimethacrylate, CQ, } \\
\text { N, N-diethanol p-toluidine water }\end{array}$ & 008618A & \multirow[b]{2}{*}{ Clearfil AP-X } & \multirow[b]{2}{*}{$00435 \mathrm{C}$} & \multirow[b]{2}{*}{$\begin{array}{l}\text { Kuraray Medical } \\
\text { Inc. Japan }\end{array}$} \\
\hline & $\begin{array}{l}\text { Bonding : } 10 \text { MDP, Bis-GMA, } \\
\text { HEMA, CQ, hydrophobic } \\
\text { dimethacrylate, N, N-diethanol } \\
\text { p-toluidine, silanated colloidal } \\
\text { silica }\end{array}$ & $00876 \mathrm{~A}$ & & & \\
\hline \multirow{3}{*}{$\begin{array}{l}\text { Total-etch System } \\
\text { Scotchbond Multi- } \\
\text { Purpose Plus } \\
\text { (Scotchbond MPP) }\end{array}$} & Etchant : 35\% phosphoric acid & J11093 & \multirow{3}{*}{ 3M Silux Plus } & \multirow{3}{*}{570340} & \multirow{3}{*}{$\begin{array}{l}\text { 3M ESPE, } \\
\text { Germany }\end{array}$} \\
\hline & $\begin{array}{l}\text { Priner : Polyalkenoic acid } \\
\text { copolymer. HEMA, water }\end{array}$ & $5 \mathrm{~W}$ & & & \\
\hline & $\begin{array}{l}\text { Bonding : Bis-GMA, HEMA, } \\
\text { photoinitiator }\end{array}$ & $5 \mathrm{~PB}$ & & & \\
\hline \multirow{2}{*}{$\begin{array}{l}\text { Glass-ionomer System } \\
\text { Reactmer Bond (RB) }\end{array}$} & $\begin{array}{l}\text { Bond A : FASG (Fluoro Alumino } \\
\text { Silicate Glass), F-PRG (full reaction } \\
\text { type pre-reacted glass-ionomer } \\
\text { fillers), water, acetone, new initiators }\end{array}$ & 080309 & \multirow[t]{2}{*}{ Reactmer } & \multirow[t]{2}{*}{070309} & \multirow[t]{2}{*}{ Shofu Inc, Japan } \\
\hline & $\begin{array}{l}\text { Bond B : 4-AET (4-acryloylethyl } \\
\text { trimellitic acid), UDMA, 2-HEMA, } \\
\text { photo-initiator }\end{array}$ & 080309 & & & \\
\hline
\end{tabular}


$50 \%$ of the surface area.

Category 3: Irregular transparency or translucency over 50\% of the surface area.

Category 4: Dentin is glossy in appearance, dark yellow or slightly brownish in color, with the majority of the dentin exhibiting translucency or transparency.

The degree of sclerosis in the sclerotic dentin was classified as Category 3 or 4 . Sclerotic dentin was glossy, yellow or dark yellow, and the sclerotic region was more than $3.0 \mathrm{~mm}$ in diameter.

\section{Adhesive agents and bonding procedures}

Table 1 lists the materials used in this study and their compositions.

Self-etch protocol: Clearfil SE Bond (CSE Bond) was applied according to the manufacturer's instructions. Self-etching primer was applied to the entire lesion with a disposable brush tip applicator (Dentsply DeTrey Gmbh, D-78467, Konstanz, Germany) and left undisturbed for 20 seconds. Volatile ingredients were evaporated with mild air and adhesive resin was applied and cured (Hilux Curing Light 250, Benlioglu, Turkey) for 10 seconds. After the bonding procedures, each lesion was restored with Clearfil AP-X composite resin in two increments and each increment was light-cured for 40 seconds.

Total-etch protocol: 3M Scotchbond MultiPurpose Plus (Scotchbond MPP) was applied according to the manufacturer's instructions. Each lesion was conditioned with $35 \%$ phosphoric acid gel for 15 seconds, then rinsed with distilled water for 20 seconds leaving the surface slightly moist. Scotchbond MPP primer was applied to the moist surface and then evaporated for five seconds. Adhesive resin was applied and light-cured for 10 seconds. After the bonding procedures, each lesion was restored with $3 \mathrm{M}$ Silux Plus composite resin in two increments and each increment was light-cured for 40 seconds.

Glass ionomer protocol: Reactmer Bond (RB) was applied according to the manufacturer's instructions. Bond liquids A and B were mixed and applied to the entire lesion with a disposable brush tip applicator and left undisturbed for 20 seconds. Following evaporation of the volatile solvent, it was cured for 20 seconds. After the bonding procedures, each lesion was restored with Reactmer composite resin in two increments and each increment was light-cured for 40 seconds.

After the restorations were completed, the specimens were stored at $37^{\circ} \mathrm{C}$ in distilled water for 24 hours.

\section{Microtensile test}

Microtensile testing ( $\mu^{\prime}$ TBS) was undertaken using the non-trimming technique that was first described by Shono et al. ${ }^{19)}$. Three 1 -mm-thick vertical slabs were cut through the entire composite-bonded tooth and perpendicular to the bonded surface using a low-speed diamond saw (Isomet, Buehler Ltd., Lake Bluff, IL, USA) under water cooling. The slabs were further sectioned into $1 \times 1 \mathrm{~mm}$ composite-dentin beams, and beams with standard dentinal thickness of approximately $2 \mathrm{~mm}$ were used for microtensile testing. The specimens were attached to a Bencor Multi-T testing apparatus (which was modified by Bernard Ciucchi, Danville Engineering Co., Danville, CA, USA) with a cyanoacrylate adhesive (Zapit, DVA, Anaheim, CA, USA), and then subjected to tensile forces in a microtensile testing machine (Multispeed Transmission, Harvard Apparatus Co., USA) at a cross-head speed of $1 \mathrm{~mm} / \mathrm{min}$. The exact dimensions of each fractured beam were determined using a digital caliper (Mitutoyo, Tokyo, Japan).

After microtensile testing, failure modes of the specimens were determined using a stereomicroscope (Olympus, Japan) at $\times 20$ magnification. Modes of failure were classified as adhesive if the failure occurred entirely within the adhesive, as cohesive in composite or cohesive in dentin if the failure occurred exclusively within the composite or within the dentin, and as mixed if the failure continued from the adhesive into either composite or dentin ${ }^{20)}$.

\section{Statistical analysis}

Bond strength data were analyzed by two-way ANOVA (sound versus sclerotic dentin; total-etch versus self-etch versus glass ionomer), and multiple comparisons were performed by post hoc Duncan's test. Data were tested at a significance level of 0.05 using a computer software (SPSS Ver. 11, SPSS Inc., Chicago, IL, USA).

\section{SEM analysis}

Three maxillary anterior teeth with deep sclerotic dentin and three teeth with artificial sound dentin on the palatal surface were used for SEM observations. The teeth were prepared in the same manner as per the bonding procedure. They were then sectioned longitudinally to the bonding surface under running water using a low-speed diamond saw. After storage for 24 hours in neutral formalin, the specimens were embedded in an epoxy resin (Epon 815, NISSIN EM Co. Ltd., Tokyo, Japan) and polished using wet silicon carbide papers and diamond pastes down to $0.25 \mu \mathrm{m}$ (DP-Paste, Struers A/S, Copenhagen, Denmark).

The specimens were subjected to argon ion etching (EIS-1E, Elionix Ltd., Tokyo, Japan) for five minutes at a constant voltage of $1 \mathrm{kV}$ and ion current density of $0.2 \mathrm{~mA} / \mathrm{cm}^{2}$, with the ion beam directed at $90^{\circ}$ to the specimen surface ${ }^{5)}$. The specimens were 
then gold sputter-coated and observed by a scanning electron microscope (JSM 5400, JEOL Ltd., Tokyo, Japan).

Representative debonded specimens from each group with $\mu$ TBS values that were close to the mean value were fixed in 10\% neutral formalin for 24 hours. They were then gold sputter-coated and observed using a scanning electron microscope.

\section{RESULTS}

\section{Microtensile bond strength}

Table 2 shows the mean microtensile bond strength ( $\mu$ TBS) values of CSE Bond, Scotchbond MPP, and $\mathrm{RB}$ to natural sclerotic and artificial sound dentin lesions. Table 3 shows the statistical analysis results. With sound dentin, CSE Bond showed a significantly higher bond strength than the other adhesive systems $(p<0.05)$, whereas with sclerotic dentin there were no significant differences in bond strength among all the adhesive groups $(p>0.05)$. The mean $\mu$ TBS values of CSE Bond and Scotchbond MPP in sound dentin were significantly higher than the bond strengths in natural lesions $(p<0.05)$. With RB, $\mu$ TBS values were not significantly different in artificial and natural lesions ( $p>0.05)$. Hence, $\mathrm{RB}$ was the only adhesive which supported the null hypothesis that there would be no differences in tensile bond strength to both sclerotic and sound palatal dentin. As for CSE Bond and Scotchbond MPP, the original null hypothesis was rejected.

\section{SEM observation}

SEM observation of the resin-dentin interfaces in sound dentin showed that CSE Bond (Fig. 1) created a 1 - $\mu$ m-thick hybrid layer, whereas the hybrid layer created with Scotchbond MPP (Fig. 2) was $3 \mu \mathrm{m}$ thick. With RB (Fig. 3), the hybrid layer could not be observed - but a thin intermediate layer could be discerned. SEM observation of the resin-sclerotic dentin interfaces in sclerotic dentin with CSE Bond (Fig. 4) and RB (Fig. 6) revealed no hybrid layer formation and resin tags. Hybrid layer created with Scotchbond MPP was $3 \mu \mathrm{m}$ thick (Fig. 5).

$\mathrm{CSE}$ Bond and $\mathrm{RB}$ could not form resin tags in the tubules of the natural sclerotic dentin, and mineral deposits were still evident in the tubules even after conditioning with phosphoric acid of the total-etch adhesive Scotchbond MPP (Fig. 5). The glass ionomer-based adhesive, Reactmer Bond, could not form any resin tags in both sclerotic dentin (Fig. 6) and artificially created sound dentin lesions (Fig. 3 ), hence resulting in equal tensile bond strength values.

\section{Failure mode analysis}

Table 4 shows the failure modes of the fractured specimens in the various groups. The predominant failure mode in sound dentin with all the adhesive systems and in sclerotic dentin with RB (Figs. 9a and b) was adhesive failure between resin and dentin. Most of the specimens bonded with CSE Bond (Figs.

Table 2 Mean microtensile bond strength values $( \pm \mathrm{SD})$ to natural sclerotic and sound dentin $(\mathrm{MPa})$

\begin{tabular}{llll}
\hline Bonding System & $\mathrm{n}$ & $\begin{array}{l}\text { Natural Sclerotic Dentin } \\
\text { Mean } \pm \text { SD }\end{array}$ & $\begin{array}{l}\text { Sound Dentin } \\
\text { Mean } \pm \text { SD }\end{array}$ \\
\hline CSE Bond & 15 & $27.36 \pm 9.67^{\mathrm{a}}$ & $45.44 \pm 9.72^{\mathrm{c}}$ \\
Scotchbond MPP & 15 & $25.66 \pm 7.19^{\mathrm{a}}$ & $33.88 \pm 6.22^{\mathrm{b}}$ \\
RB & 15 & $24.99 \pm 7.30^{\mathrm{a}}$ & $28.29 \pm 5.15^{\mathrm{a}}$ \\
\hline
\end{tabular}

Means identified by different superscript letters are significantly different $(\mathrm{p}<0.05)$

Table 3 Statistical analysis of microtensile bond strength results using two-way ANOVA analysis of variance

\begin{tabular}{|c|c|c|c|c|c|}
\hline Source & Type III Sum of Squares & df & Mean Square & $\mathrm{F}$ & Sig. \\
\hline Corrected Model & $4,531,059$ (a) & 5 & 906,212 & 15,161 &, 000 \\
\hline Intercept & $86,151,246$ & 1 & $86,151,246$ & $1,441,361$ &, 000 \\
\hline Dentin types & $2,191,831$ & 1 & $2,191,838$ & 36,671 &, 000 \\
\hline Bonding systems & $1,489,756$ & 2 & 744,873 & 12,462 &, 000 \\
\hline $\begin{array}{l}\text { Dentin types* } \\
\text { Bonding systems }\end{array}$ & 849,466 & 2 & 424,733 & 7,106 & ,001 \\
\hline Error & $5,020,743$ & 84 & 59,771 & & \\
\hline Total & $95,703,048$ & 90 & & & \\
\hline Corrected Total & $9,551,802$ & 89 & & & \\
\hline
\end{tabular}

a R Squared $=, 474$ (Adjusted R Squared $=, 443$ ) 


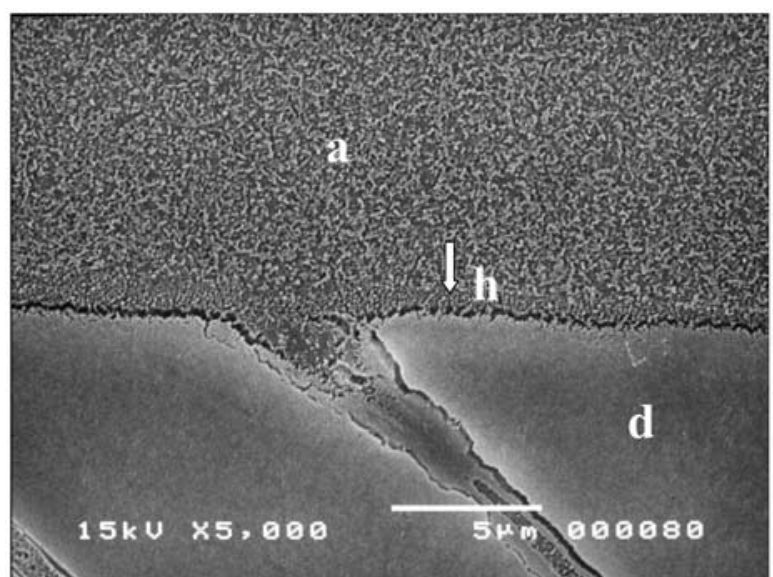

Fig. 1 Resin-dentin interface in sound dentin created with CSE Bond, where a: filled adhesive, h: hybrid layer (arrow), and d: dentin.

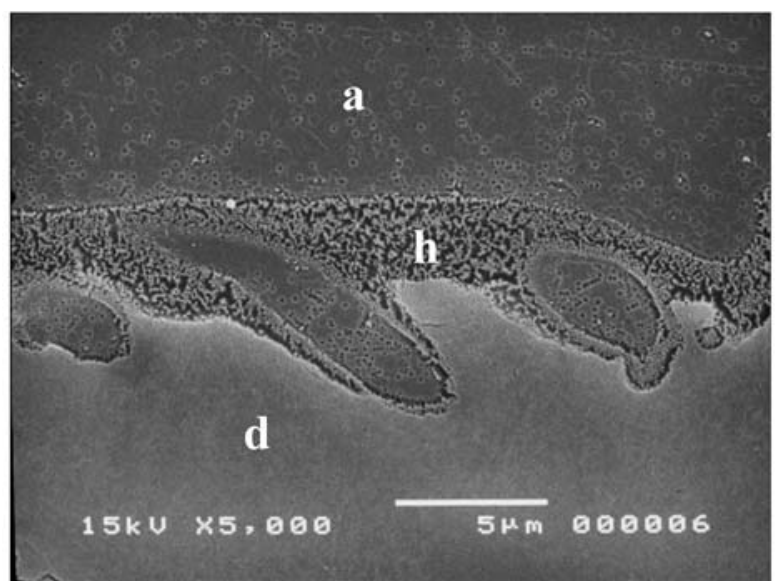

Fig. 2 Resin-dentin interface in sound dentin created with Scotchbond MPP, where a: adhesive containing polyalkenoate-based electron dense particles, h: hybrid layer, and d:dentin.

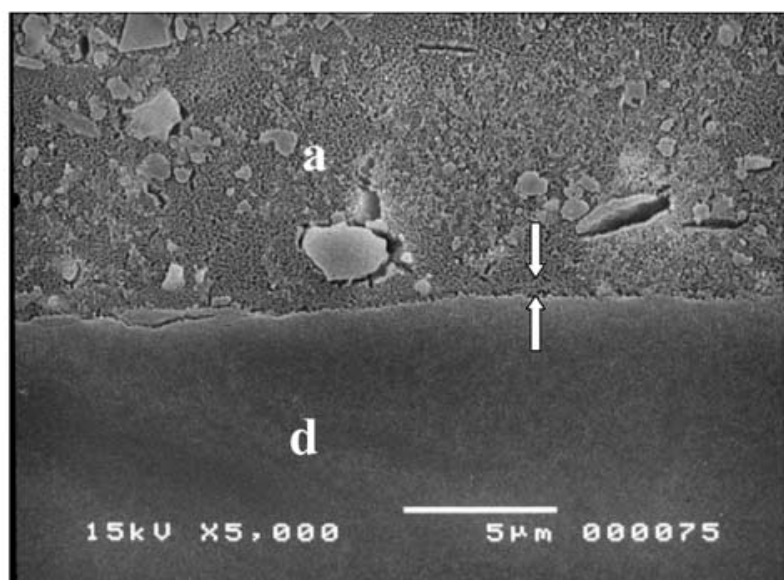

Fig. 3 Resin-dentin interface in sound dentin created with RB, where a: adhesive containing FASG and F-PRG fillers and d: dentin. A shallow intermediate hybridized layer (arrow) was apparent.

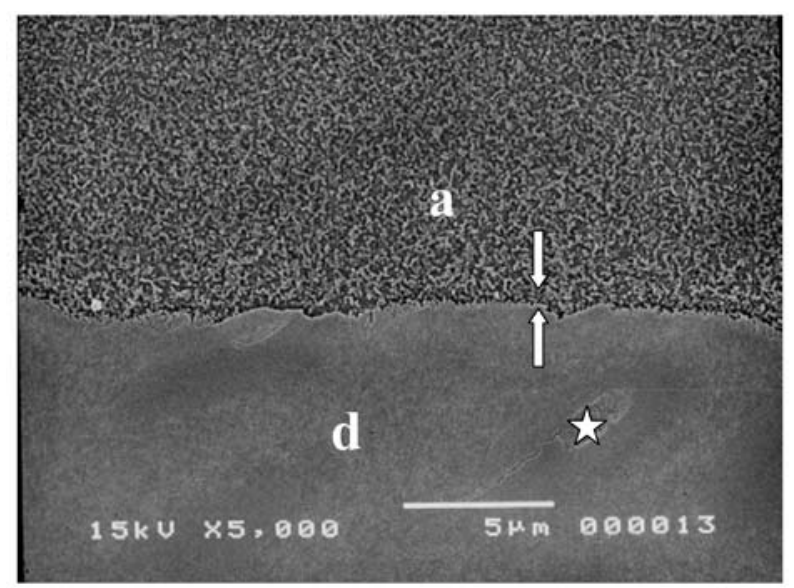

Fig. 4 Resin-sclerotic dentin interface in natural sclerotic dentin created with CSE Bond, where a: filled adhesive, star: occluded tubule, and $\mathrm{d}$ : dentin. Hybrid layer was not evident, but a thin intermediate layer (arrow) was apparent.

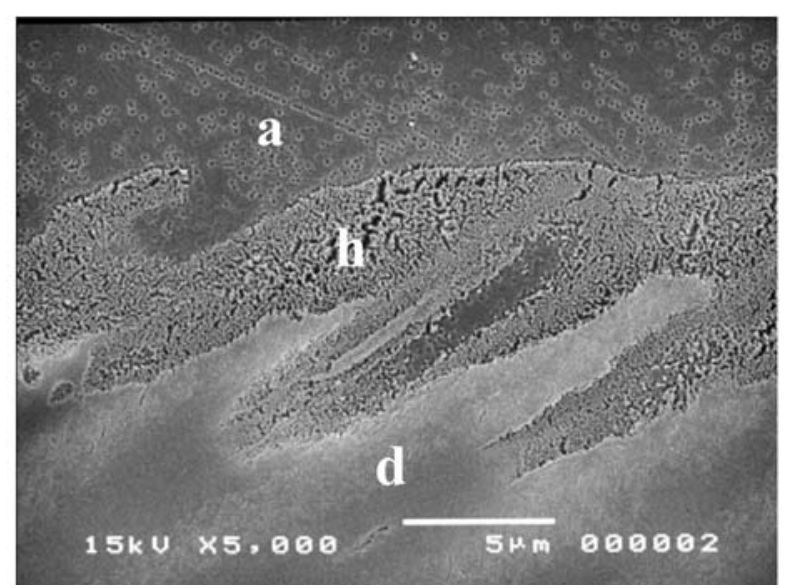

Fig. 5 Resin-sclerotic dentin interface in natural sclerotic dentin created with Scotchbond MPP, where a: adhesive containing polyalkenoate-based electron dense particles, h: hybrid layer, d: dentin.

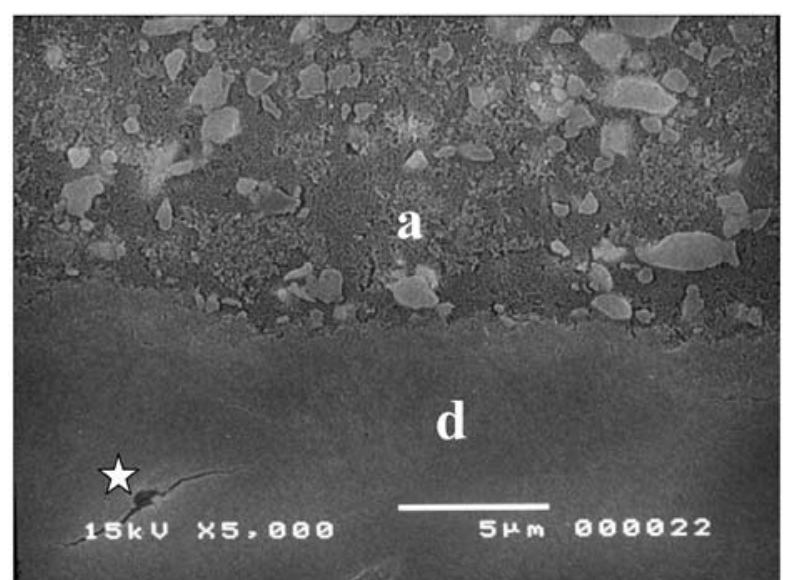

Fig. 6 Resin-sclerotic dentin interface in natural sclerotic dentin created with RB, where a: adhesive containing FASG and F-PRG fillers, star: occluded tubule, d: dentin. Hybrid layer was not evident. 
Table 4 Failure modes of specimens after microtensile bond test

\begin{tabular}{|c|c|c|c|c|c|c|c|c|}
\hline \multirow{2}{*}{$\begin{array}{l}\text { Groups } \\
\text { CSE Bond (NSD) }\end{array}$} & \multicolumn{2}{|c|}{ Adhesive } & \multicolumn{2}{|c|}{ Mixed } & \multicolumn{2}{|c|}{ Cohesive in composite } & \multicolumn{2}{|c|}{ Cohesive in dentin } \\
\hline & 3 & $20 \%$ & 9 & $60 \%$ & 1 & $6.7 \%$ & 2 & $13.3 \%$ \\
\hline CSE Bond (SD) & 2 & $13.3 \%$ & 12 & $80 \%$ & 1 & $6.7 \%$ & - & - \\
\hline Scotchbond MPP (NSD) & 3 & $20 \%$ & 8 & $53.3 \%$ & 2 & $13.3 \%$ & 2 & $13.3 \%$ \\
\hline Scotchbond MPP (SD) & 3 & $20 \%$ & 11 & $73.3 \%$ & - & - & 1 & $6.7 \%$ \\
\hline RB (NSD) & 7 & $46.7 \%$ & 4 & $26.7 \%$ & 2 & $13.3 \%$ & 2 & $13.3 \%$ \\
\hline $\mathrm{RB}(\mathrm{SD})$ & 8 & $53.3 \%$ & 4 & $26.7 \%$ & 1 & $6.7 \%$ & 2 & $13.3 \%$ \\
\hline
\end{tabular}

NSD : Natural Sclerotic dentin ; SD : Sound dentin ; Adhesive : The failure occurred entirely within the adhesive, Mixed : The failure continued from the adhesive into either in composite or dentin, Cohesive in composite : The failure occurred exclusively wihtin the composite, Cohesive in dentin : The failuer occurred exclusively within the dentin.

a)

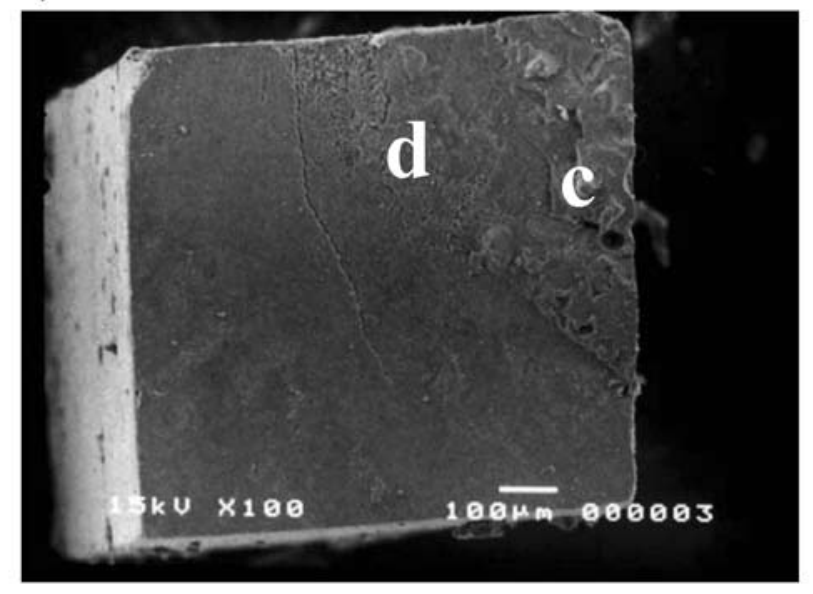

b)

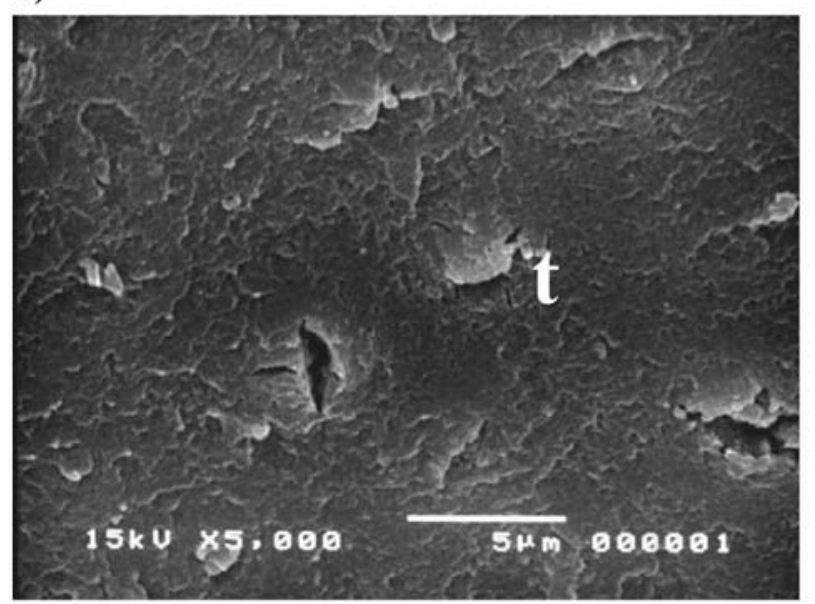

Fig. 7 (a) Scanning electron micrograph of a fractured beam taken from a natural sclerotic dentin that was bonded with CSE Bond. A mixed failure mode could be observed, with cohesive failure within the composite (c) and dentin (d).

(b) A higher magnification of the dentin site in Fig. 7(a). Tubular orifices (t) were evident but the self-etching primer system could not infiltrate into the tubules. a)

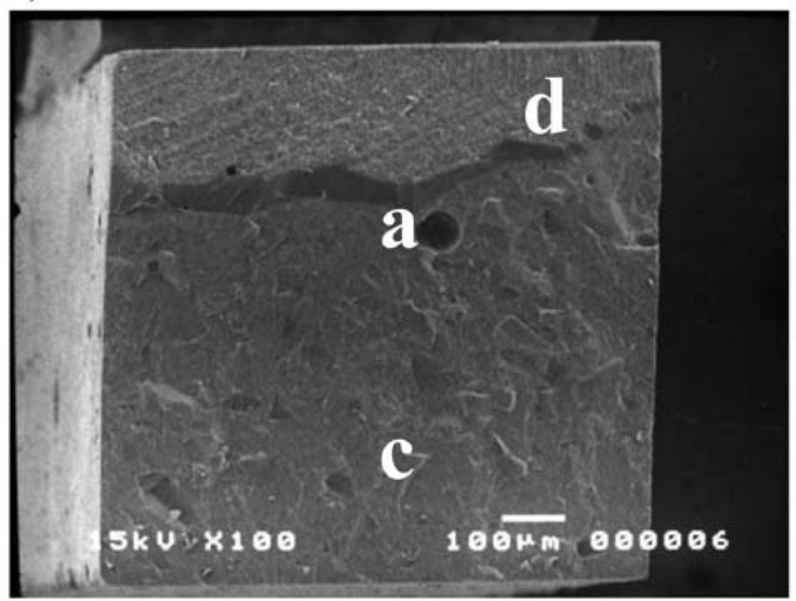

b)

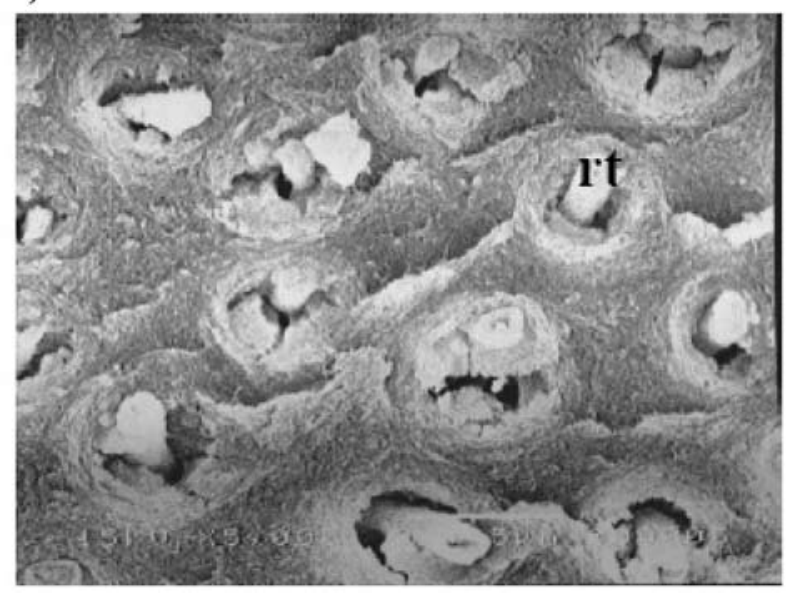

Fig. 8 (a) Scanning electron micrograph of a fractured beam taken from a natural sclerotic dentin that was bonded with Scothbond MPP. A mixed failure mode could be observed, with cohesive failure within the composite (c), adhesive (a), and dentin (d).

(b) A higher magnification of the dentin site in Fig. 8(a). Numerous resin tags (rt) could be seen, and failure occurred at the base of the hybrid layer. 
a)

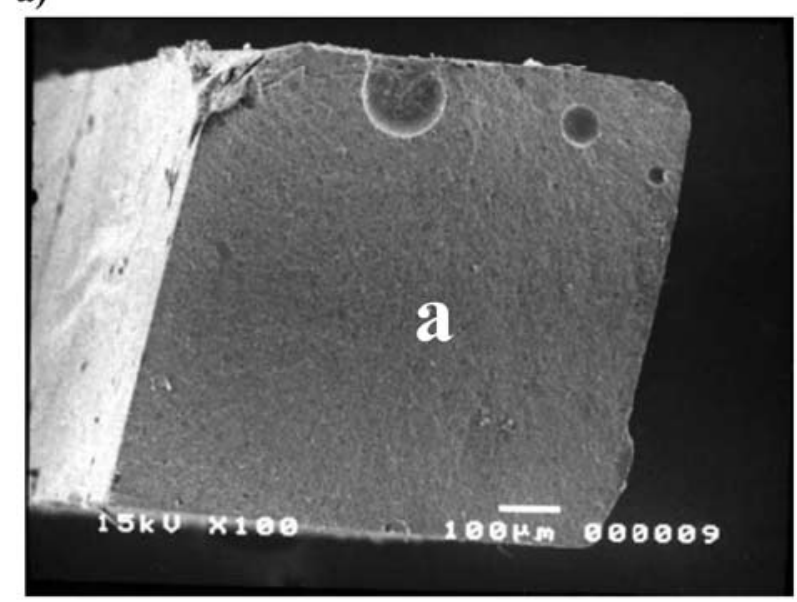

b)

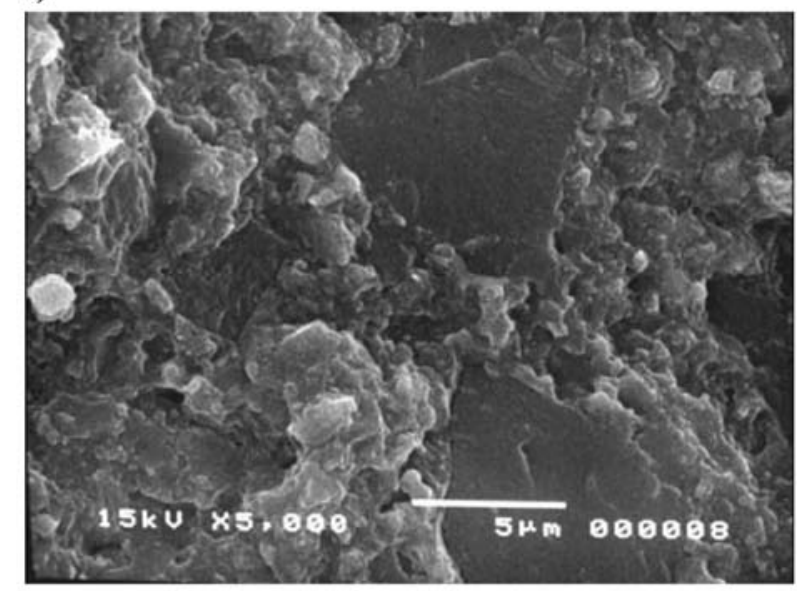

Fig. 9 (a) Scanning electron micrograph of a fractured beam taken from a natural sclerotic dentin that was bonded with Reactmer. The specimen failed cohesively within the adhesive (a).

(b) A higher magnification of Fig. 9(a).

7a and b) and Scotchbond MPP (Figs. 8a and b) in sclerotic dentin showed a mixed failure pattern, i.e., a combination of cohesive and adhesive failures.

\section{DISCUSSION}

Results of this study indicated that the bond strengths to sclerotic dentin with the self-etch adhesive CSE Bond and the total-etch adhesive Scotchbond MPP were significantly lower than those to artificially created dentin lesions. However, with $\mathrm{RB}$, almost equal bond strength values to both sound and sclerotic dentin were yielded. These findings were in agreement with similar studies in published literature $\mathrm{e}^{12,21,22)}$.

Some dentinal tubules of sclerotic dentin were found to be obliterated by mineralized deposits.
These deposits might have come from salivary minerals or minerals in dentinal fluid, or from both sources. They then interfere with both acid penetration and subsequent resin infiltration ${ }^{11}$. Length of the resin tags does not contribute to bond strength ${ }^{7)}$. However, resin tag hybridization to peritubular dentin is considered important for reliable bonding ${ }^{23)}$. Therefore, the primary reason for the lower bond strengths to natural sclerotic dentin lesions as compared with artificial sound dentin lesions might be the inhibition of resin tag formation with the self-etch adhesive CSE Bond (Fig. 4 and Fig. $7 \mathrm{~b}$ respectively) and the loosely packed resin tags with the total-etch adhesive Scotchbond MPP (Fig. 5 and Fig. $8 \mathrm{~b}$ respectively).

Thickness of the hybrid layer depends on the bonding system (total-etch versus self-etch), regional differences in dentin (superficial versus deep), and type of dentin (sound, sclerotic, or caries-affected) ${ }^{24)}$. Self-etch systems such as CSE Bond ${ }^{14)}$ and glass ionomer-based adhesive systems such as $\mathrm{RB}^{25,26)}$ produced very thin hybrid layers when they were applied to sound dentin. Hybrid layer thickness to sclerotic dentin was found to be much lower than that observed in sound dentin ${ }^{8,27)}$. In this study, the mild self-etch adhesive CSE Bond created a hybrid layer of about $1 \mu \mathrm{m}$ in sound dentin (Fig. 1), whereas the glass ionomer-based adhesive $\mathrm{RB}$ resulted in only a thin intermediate layer (Fig. 3). The hybrid layer created with the total-etch adhesive Scotchbond MPP to sound dentin was $3 \mu \mathrm{m}$ (Fig. 2). Consistent with previous research data, hybrid layer thickness did not correlate with bond strength ${ }^{24,28)}$. Scotchbond MPP, CSE Bond, and RB showed similar bond strengths to sclerotic dentin ( $p>0.05)$, although SEM observation of the resin-sclerotic dentin interfaces indicated otherwise. The hybrid layers of CSE Bond (Fig. 4) and RB (Fig. 6) could not be discerned, whereas the thickness of the hybrid layer created with Scotchbond MPP was $3 \mu \mathrm{m}$ (Fig. 5), the same as that in sound dentin.

Sakoolnamarka et $a .^{29)}$ and Kwong et al. ${ }^{21)}$ reported that hybrid layers to cervical sclerotic lesions varied in thickness due to the hypermineralization of the sclerotic dentin surface, making it acidresistant $^{8,11)}$. Similarly, sclerotic dentin found on the palatal region might also have a hypermineralized surface layer which would not come into contact with the opposite tooth, hence affecting resin infiltration into intertubular dentin. On this suggestion, it is yet to be substantiated by TEM analysis - which would provide additional information on the structure of sclerotic dentin found in natural palatal lesions.

Mild self-etch systems, like CSE Bond, generally have a $\mathrm{pH}$ of about 2 and demineralize dentin only to a depth of $1 \mu \mathrm{m}$, keeping residual hydroxyapatite still attached to collagen ${ }^{16}$. The preservation of 
hydroxyapatite within the submicron hybrid layer may serve as a receptor for additional chemical bonding along with micromechanical interlocking through hybridization. In this respect, 10-MDP (10methacryloxydecyl dihydrogen phosphate) in CSE (Table 1) has been shown to have a chemical bonding potential to calcium of residual apatite ${ }^{17)}$.

On the adhesion of glass ionomers to tooth substrates, micromechanical interlocking is achieved by shallow hybridization of the microporous apatitecoated collagen fibril network ${ }^{30)}$, whereas true primary chemical bonding occurs through forming ionic bonds between the carboxyl groups of the polyalkenoic acid and calcium of hydroxyapatite ${ }^{31)}$. RB may be classified as a one-step, self-etching FPRG giomer as it contains ion-leachable fluoroaluminosilicate glass (FASG) and the adhesion promoting monomer 4-AET (4-acryloethyltrimellitic acid), which has the ability to form hydrogen bonds with dentin collagen. The major feature of this material is re-chargeable full pre-reacted glass ionomer filler (F-PRG), where the entire filler particle is attacked by polyacrylic acid. This feature thus provides the potential of chemical bonding via an ion exchange process between the glass particles and partially demineralized tooth substrates ${ }^{26,31-33)}$.

In a study by Özer et al. ${ }^{34)}$, it was found that aging did not cause any decrease in bond strength of $\mathrm{RB}$ as it was in an self-etch bonding system (Clearfil Protect Bond). They attributed these results to the sclerotic structure of aged teeth ${ }^{34)}$. The chemical bonding potential of the mild self-etch system CSE Bond and the glass ionomer-based adhesive system RB thus accounted for their similar tensile bond strengths as the total etch system Scotchbond MPP to sclerotic dentin despite the lack of resin tags.

Adhesive failure accounted for majority of the failures in sound dentin with different adhesive systems (Table 4). Most of the specimens bonded to natural sclerotic dentin with CSE Bond (Fig. 7a) and Scotchbond MPP (Fig. 8a) showed a mixed failure pattern, a combination of cohesive and adhesive failures.

One recent clinical study compared the cumulative retention rates of a resin-modified glass ionomer cement (Fuji II LC), a two-step selfetching primer adhesive (Clearfil SE Bond), and a phosphoric acid etch single-bottle adhesive (Single Bond) when used to restore natural sclerotic dentin lesions ${ }^{35)}$. Unlike our findings, this study by Burrow and Tyas $^{35)}$ reported that resin-modified glass ionomer cement was the best material for restoring noncarious cervical legions, if esthetics were not a critical consideration. Cumulative retention rate of resin-modified glass ionomer cement was higher than the other two systems after three years' recall. It is noteworthy that results with adhesive systems may change under clinical conditions.

\section{CONCLUSIONS}

The conclusions of this study can be summarized as follows:

1. The bonding systems used in this study rendered equal performance on sclerotic dentin surfaces.

2. The bond strength values of CSE Bond and Scotchbond MPP decreased significantly on sclerotic palatal dentin surfaces.

3. The bond strength values of RB did not change significantly according to dentin surface type (sclerotic versus sound dentin).

\section{ACKNOWLEDGEMENTS}

This research project was supported by Scientific Research Foundation of Selcuk University.

\section{REFERENCES}

1) Rose WF, Haveman CW, Davis DR. Fundamentals of operative dentistry, 3rd ed, Quintessence Pub Co., Illinois, 2006, pp.37-67.

2) Bader JD, McClure F, Scurria MS, Shugars DA, Heymann HO. Case-control study of noncarious cervical lesions. Commun Dent Oral Epidemiol 1996; 24: 286-291.

3) Bartlett DW, Evans DF, Anggiansah A, Smith BG. A study of the association between gastrooesophageal reflux and palatal dental erosion. $\mathrm{Br}$ Dent J 1996; 181: 125-131.

4) Lussi A, Jaeggi T, Zero D. The role of diet in the aetiology of dental erosion. Caries Res 2004; 38: 3444 .

5) Imfeld T. Tooth erosion. Int Dent J 1996; 46: 236240.

6) Bishop K, Kelleher M, Briggs P, Joshi R. Wear now? An update on the etiology of tooth wear. Quintessence Int 1997; 28: 305-313.

7) Swift EJ, Perdigao J, Heymann HO. Bonding to enamel and dentin: a brief history and state of the art. Quintessence Int 1995; 26: 95-110.

8) Van Meerbeek B, Braem M, Lambrechts P, Vanherle G. Morphological characterization of the interface between resin and sclerotic dentin. J Dent 1994; 22: 141-146.

9) Yoshiyama M, Suge T, Kawasaki A, Ebisu S. Morphological characterization of tube-like structures in hypersensitive human radicular dentin. J Dent 1996; 24: 57-63.

10) Nicholson JW. Fundamentals of operative dentistry, 3rd ed, Quintessence Pub Co., Illinois, 2006, pp.1-36.

11) Mixson JM, Spencer P, Moore DL, Chappell RP, Adams S. Surface morphology and chemical characterization of abrasion/erosion lesions. Am J Dent 1995; 8: 5-9.

12) Yoshiyama M, Sano H, Ebisu S, Tagami J, Ciucchi B, Carvalho RM, Johnson MH, Pashley DH. Regional 
strengths of bonding agents to cervical sclerotic root dentin. J Dent Res 1996; 75: 1404-1413.

13) El-din AK, Miller BH, Griggs JA. Resin bonding to sclerotic, noncarious, cervical lesions. Quintessence Int 2004; 35: 529-540.

14) Tay FR, Kwong SM, Itthagarun A, King NM, Yip HK, Moulding KM, Pashley DH. Bonding of a self-etching primer to noncarious cervical sclerotic dentin: Interfacial ultrastructure and microtensile bond strength evaluation. J Adhes Dent 2000; 2: 9-28.

15) Tay FR, Pashley DH. Resin bonding to cervical sclerotic dentin: a review. J Dent 2004; 32: 173-196.

16) Van Meerbeek B, De Munck J, Yoshida Y, Inoue S, Vargas M, Vijay P, Van Landuyt K, Lambrechts P, Vanherle G. Adhesion to enamel and dentin: Current status and future challenges. Oper Dent 2003; 28: 215-235.

17) Van Meerbeek B, Van Landuyt K, De Munck J, Inoue S, Yoshida Y, Perdigão J, Lambrechts P, Peumans M. Fundamentals of operative dentistry, 3rd ed, Quintessence Pub Co., Illinois, 2006, pp.183260.

18) Heymann HO, Bayne SC. Current concepts in dentin bonding: focusing on dentinal adhesion factors. J Am Dent Assoc 1993; 124: 26-36.

19) Shono $Y$, Ogawa T, Terashita M, Carvalho RM, Pashley EL, Pashley DH. Regional measurement of resin-dentin bonding as an array. J Dent Res 1999; 78: 699-705.

20) Inokoshi S, Hosoda H, Harnirattisai C, Shimada Y. Interfacial structure between dentin and seven dentin bonding systems revealed using argon ion beam etching. Oper Dent 1993; 18: 8-16.

21) Kwong SM, Cheung GSP, Kei LH, Itthagarun A, Smales RJ, Tay FR, Pashley DH. Microtensile bond strengths to sclerotic dentin using a self-etching and a total-etching technique. Dent Mater 2002; 18: 359369.

22) Lopes GC, Vieira LC, Monteiro S, Caldeira de Andrada MA, Baratieri CM. entin bonding: effect of degree of mineralization and acid etching time. per Dent 2003; 28: 429-439.

23) Van Meerbeek B, Conn LJ Jr, Duke ES, Eick JD, Robinson SJ, Guerrero D. Correlative transmission electron microscopy examination of nondemineral- ized resin-dentin interfaces formed by two dentin adhesive systems. J Dent Res 1996; 75: 879-888.

24) Prati C, Chersoni S, Mongiorgi R, Pashley DH. Resin infiltrated dentin layer formation of new bonding systems. Oper Dent 1998; 23: 185-194.

25) Miyazaki M, Iwasaki K, Onose H. Adhesion of single application bonding systems to bovine enamel and dentin. Oper Dent 2002; 27: 88-94.

26) Tay FR., Sano H, Tagami J, Hashimoto M, Moulding KM, Yiu C, Pashley DH. Ultrastructural study of a glass ionomer based, all-in-one adhesive. J Dent 2001; 29: 489-498.

27) Prati C, Chersoni S, Mongiorgi R, Montanari G, Pashley DH. Thickness and morphology of resininfiltrated dentin layer in young, old, and sclerotic dentin. Oper Dent 1999; 24: 66-72.

28) Yoshiyama M, Carvalho RM, Sano H, Horner JA, Brewer PD, Pashley DH. Regional bond strengths of resins to human root dentine. J Dent Res 1996; 24: 435-442.

29) Sakoolnamarka R, Burrow Mf, Tyas MJ. Micromorphological study of resin-dentin interface of non-carious cervical lesions. Oper Dent 2002; 27: 493-499.

30) Tay FR, Smales RJ, Ngo H, Wei SH, Pashley DH. Effect of different conditioning protocols on adhesion of a GIC to dentin. J Adhes Dent 2001; 3: 153-167.

31) Yoshida Y, Van Meerbeek B, Nakayama Y, Snauwaert J, Hellemans L, Lambrechts P, Vanherle G, Wakasa K. Evidence of chemical bonding at biomaterial-hard tissue interfaces. J Dent Res 2000; 79: 709-714.

32) Nezu T, Winnik FM. Interaction of water-soluble collagen with polyacrylic acid. Biomaterials 2000; 21: 415-419.

33) Sennou HE, Lebugle AA, Gregoire GL. X-ray photoelectron spectroscopy study of the dentin-glass ionomer cement interface. Dent Mater 1999; 15: 229-237.

34) Özer F, Sengun A, Ozturk B, Say EC, Tagami J. Effect of tooth age on microtensile bond strength of two fluoride-releasing bonding agents. J Adhes Dent 2005; 7: 289-295.

35) Burrow MF, Tyas MJ. Clinical evaluation of three adhesive systems for the restoration of non-carious cervical lesions. Oper Dent 2007; 32: 11-15. 